\title{
Zur Bestimmung des Kartoffelgehaltes in Brote.
}

\author{
Erwiderung zu den Bemerkungen von Klostermann und Scholta. \\ Von
}

J. Abel in Mannheim.

Auf meine Bemerkungen ${ }^{1}$ ) zu der Abhandlung von Klostermann und Scholta über obiges Thema haben die Genannten Gegenbemerkungen ${ }^{2}$ ) veröffentlicht, worin sie meine Ausführungen einer in der Hauptsache unzutreffenden Kritik unterziehen und zugleich den Vorwurf gegen mich erheben, daß ich in meinen Bemerkungen nicht ganz sachlich geblieben sei. Ich sehe mich dadurch zu folgender Erwiderung veranlaßt:

Bei seinen ersten Arbeiten über die Bestimmung des Alkalitätswertes der Aschen hatte Farnsteiner sich von der Ansicht leiten lassen, daß der Kohlensäuregehalt der Asche ein Maßstab für die gesuchte Alkalität derselben sei. Im weiteren Verlauf seiner Studien drängte sich ihm indessen die Utberzeugung auf, daß diese Annahme unrichtig sei, und er suchte daher und fand anch ein Verfabren der Alkalitätsermittelung, das wohl umständlicher als die Koblensäurebestimmung ist, das aber die Fehler und Mängel der letzteren vermeidet. Ich habe dann das Farnsteiner'sche Verfahren bei der Prüfung des Mehles und Brotes auf einen Kartoffelzusatz in Anwendung gebracht und bei den - allerdings nicht ron Hause aus alkalischen, aber dureh den Zusatz von überschüssiger Soda alkalisch gemachten - Aschen der Mehle Werte erhalten, durch welche die Auffassung über die Nichtäquivalenz von Kohlensäuregehalt und Alkalität bestätigt wird. Klostermann und Scholta, die sich danach mit dem gleichen Gegenstand beschäftigten, bestimmten die Alkalität nach anderem Verfahren titrimetrisch und erklärten eine gesonderte Kohlensäurebestimmung zum Zwecke der Ermittelung der unverändert gebliebenen Soda für überflüssig, weil ja Alkalität und Kohlensäuregehalt äquivalent seien. Die Bedenken, welche Farnsteiner, der die Frage des Verhältnisses zwischen Kohlensäuregehalt und Alkalität der Asche auf das Gründlichste und systematisch untersucht hat, gegen die Inbeziehungsetzung der beiden Größen zu einander hatte, und infolge deren er dazu kam, den Kohlensäuregehalt als Maßstab für die Aschenalkalität vollständig zu verwerfen, erwähnen sie mit keinem Worte.

Indem ich nun das Klostermann und Scholta'sehe Verfahren der Alkalitätsbestimmung im Rahmen der ganzen bisherigen Entwicklung der Frage besprach und dabei hervorhob, daß das Ende derselben zu dem von Farnstein er schon als irrtümlich erkannten Anfang wieder zurückgekehrt sei, also einen echten und rechten Circulus vitiosus darstello, kann ich nicht erkennen, worin von Klostermann und Scholta das Unsachliche meiner Kritik gefunden wird.

Im übrigen polemisieren Klostermann und Scholta nicht nur gegen meine Auffassung der rationellsten Alkalitätsermittelung, sondern im Grunde genommen auch gegen ihre eigene. Denn wenu ibre Ansicht richtig wäre, daß der Koblensäuregehalt der Aschenalkalität äquivalent ist, und dafo sich daher aus der Alkalităt der Koblensäuregehalt einer Asche und umgekehrt aus dem Kohlensäuregehalt die Alkalität errechnen ließe, dann ist mein Verfahren allerdings zu umständlich, aber das ibrige auch. Dann wäre ja nur die nach der Aschenherstellung noch sich vorfindende Kohlensäure von der ursprünglich in Form von Soda zugesetzlen abzuziehen und daraus die negative Aschenalkalität ohne weiteres zu berechnen. Die einfacbste und genaueste Alkalitätsermittelung wäre dann - eine Koblensäurebestimmung, die bei Beob-

1) Diese Zeitschrift 1917, 33, 115-117.

2) Drese Zeitschrift 1917, 33, 306-308. 
achtung einiger Vorsicht sehr sichere und sehr genaue Resultate liefert, und die nicht mehr als eine Stunde Zeit in Anspruch nimmt.

Nicht ganz so unbegründet wie der oben erwähnte Vorwurf der Unsachlichkeit meiner Kritik erscheint nach ihren erläuternden Darlegungen die Art und Weise, wie Klostermann und Scholta den Begriff "Asche" gebrauchen. Es wurde von mir bemängelt, dass sie den Chlorgehalt als Kochsalz von dem erhaltenen Glührückstand der Mehle abziehen und in Abweichung von der bisherigen Übung diese Größe dann als "Asche" bezeichnen. Darauf wandten Klostermann und Scholta ein, daR man bei Untersuchung des Brotes ja ebenfalls das Chlor bestimmen und von dem Glührückstand als Chlornatrium in Abzug bringen müsse.

Es ist zuzugeben, daß dieser Grund Gewicht hat, und dab das von Kloster mann und Scholta angewandte Verfahren berechtigt erscheint, wenn und soweit man von der Geltendmachung des Einwandes absieht, daß der Natriumgehalt der Mehle zur Bindung der vorhandenen Chlormenge bei weitem nicht ausreicht, und daß die Berechnung des Chlors als Kochsalz daher nur als Notbehelf angesehen werden kann. Ich habe vorgezogen, den Begriff "Asche" in dem bisher üblich gewesenen Sinne zu gebrauchen, und habe mir nur Rechenschaft zu geben versucbt, wie groß der daraus sich ergebende Fehler bei der Brotuntersuchung sein könnte. Bei dem Klostermann und Scholta'schen Verfahren befremdet es jedenfalls, daß sie die Bezeichnung "Asche" in einem mit der bisherigen Ubung zweifellos nicht in Einklang stehenden Sinne gebrauchen, und daß sie dieses Abweichen von dem Hergebrachten mit Stillschweigen übergehen.

Wenn einerseits Klostermann und Scholta das Recht für sich in Anspruch nehmen, was ihnen natürlich niemand bestreiten kann, daß sie sich eines herkömmlichen Begriffes mit einer durch das praktische Bedürfnis gebotenen Abänderung bedienen, so hat andererseits die Fachwelt auch das Recht zu verlangen, daß von dem Einzelnen auf dieses Abgehen von der Gewohnheit ausdrücklich hingewiesen wird, und daß ihr nicht zugemutet wird, den Begriff mit seinem neuen Inbalt aus den Versuchsergebnissen und aus dem Zusammenhang der Darstellung sich erst zu rekonstruieren.

Auf die von anderer Seite zu demselben Gegenstande bereits vorliegende Veroffentlichung ${ }^{1}$ ) bin ich erst nachträglich aufmerksam geworden. Daß ich die Arbeit von $\mathrm{R} \ddot{z} z$ senyi nicht gekannt habe, und sie infolgedessen auch nicht erwäbnen konnte, bedauere ich - nicht etwa, weil mir diese Arbeit hätle von Nutzen sein können; denn meine Überlegungen und Vérsuche wären mit und ohne Kenntnis dieser Arbeit ganz die gleichen gewesen - sondern einmal deshalb, weil ich jedem das Seine lassen will, und sodann, weil die Nichterwähnung der Arbeiten anderer da, wo man seinen Berufsgenossen nicht ganz trauen zu dürfen glaubt, leicht den Verdacht entstehen läßt, man hätte von diesen Arbeiten gewußt und davon absichtlich geschwiegen.

Und so bleibt mir meine Meinungsgegner nur noch auf eines hinzuweisen übrig. Klostermann und Scholta haben gegen mich den Vorwurf erhoben, dab ich in meinen Ausführungen zu ihrer Arbeit nicht ganz sachlich geblieben sei, ohne daß für mich ersichtlich ist, worin das Unsachliche meiner Kritik liegen soll. Alle Welt ist sich nun darüber einig, daß den wissenschaftlichen Fortschritt stört und einen Tadel verdient, wer in die Erörterung einer wissenschaftlichen Angelegenheit ein unsachliches Moment hineinträgt; sie ist sich aber auch darüber einig, daß die Erhebung des Vorwurfes der Unsachlichkeit da, wo sie zu. Unrecht geschieht, - ein Pfeil ist, der auf den Absender zurückprallt.

1) Chem.-Ztg. 1907, 31, 559. 